Original Research Article

\title{
KAP on antibiotic usage and resistance among second professional medical students
}

\author{
Kanika Khajuria, Sharminder Kaur*, Shamiya Sadiq, Vijay Khajuria
}

Department of Pharmacology and Therapeutics, GMC, Jammu, Jammu and Kashmir, India

Received: 01 October 2018 Accepted: 26 October 2018

\section{*Correspondence to:}

Dr. Sharminder Kaur, Email: joharsharminder@ gmail.com

Copyright: (C) the author(s), publisher and licensee Medip Academy. This is an openaccess article distributed under the terms of the Creative Commons Attribution NonCommercial License, which permits unrestricted noncommercial use, distribution, and reproduction in any medium, provided the original work is properly cited.

\begin{abstract}
Background: Antibiotics are wonder drugs as they prevent and treat bacterial infections. However, their irrational use even by wrong prescribing behaviour of physician leads to antibiotic resistance medical students are future doctors and are provided knowledge and practice of antibiotics in treatment, and prevention of diseases in their study curriculum of second professional course mainly in chapters of pharmacology and microbiology. Therefore, the present study was to determine the second-year medical students' knowledge, attitude and perception regarding antimicrobial use and resistance.

Methods: Study was conducted on second professional undergraduate medical students from Government Medical College, Jammu. 140 students participated, and informed consent was taken prior to study. A validated questionnaire comprised of 20 questions was provided to them and responses were recorded. Questionnaire was comprised of 20 questions (13 questions attributed to knowledge of antibiotics usage and resistance, six to attitude and one question regarding perception).

Results: The students showed fair knowledge about antibiotics and resistance. Percentages of fully correct answers was between 63-100\% regarding knowledge of antibiotics. The attitude results revealed that self-medication by the student was observed in $67 \%$, while $70 \%$ agreed that they had left over antibiotics at home, but only $42 \%$ committed that they take these left over antibiotics. As far as practice was concerned the maximum students consult text books as source of knowledge regarding resistance followed by Wikipedia.

Conclusions: The current study observed high score of knowledge than attitude in medical students regarding antibiotic usage and resistance and increasing influence of internet like Wikipedia. This underscores the need for more effort in updating the students regarding antibiotic usage and resistance and laying more emphasis in the core curriculum of their academics.
\end{abstract}

Keywords: Attitude, Antibiotics, Knowledge, Medical students, Practice, Resistance

\section{INTRODUCTION}

One of the defining moments in the human race in its fight to combat morbidity and attain longevity was the development of antibiotics. It revolutionized the treatment in the post-world war era. But today wheel of time has turned over and in present scenario biggest threat to save lives is resistance to these very antimicrobials.

WHO rightly recognized antibiotic resistance as one of the biggest threats to global health, food security, and development and endorsed a global action plan on antimicrobial resistance, including antibiotic resistance in May 2015 in its World Health Assembly. Top of its five 5 strategic objectives is to improve awareness and understanding of antimicrobial resistance. ${ }^{2}$

It is the bacteria and not the human that becomes resistant to antibiotics due to inadequate treatment and acquires ability to withstand antibiotics, so much so that sometimes they learn to thrive on them. Though antibiotics resistance is a global problem but in developing countries where population has less access to the medical institutions, it appears to a major public health issue. According to 
reports, it accounts for 7 lakhs deaths worldwide and in addition causes huge economic loss that ranges between $\$ 2.1$ trillion and \$124.5 trillion. ${ }^{3}$ New Delhi bug became a global issue in 2008 as patients were found to have this dreaded multi drug resistant bacteria. ${ }^{4}$

Though there is an antibiotic management policy in India, yet the implementation is not strict, and situation is further compounded by self-prescription. Medical students are future doctors and are provided knowledge and practice of antibiotics in treatment, and prevention of diseases during their study period of five years and one year of internship. The study curriculum in second professional medical students related to antibiotic use and resistance is mainly in chapters of pharmacology and microbiology and they become competent to prescribe antimicrobials after training and examination

Therefore, the present study was aimed to determine the second year medical students knowledge, attitude and perception regarding antimicrobial use and resistance. Knowledge imparted during their preclinical study course forms the very basis of prescribing of antibiotics which is further later refined by senior clinicians during their clinical postings.

Since, WHO currently emphasises to improve awareness and understanding of antimicrobials and behaviour in relation to their use, we hope that results of current study shall provide insight to this problem, thereby improving the future doctors' prescription of antimicrobials.

\section{METHODS}

Present study was conducted on second professional undergraduate medical students from Government Medical College Jammu after taking clearance from institutional ethics committee. (vide no IECs I /18c/2017/410). 150 students were informed about the objectives of the study. Out of 150 students, 140 agreed to voluntarily participate comprising of 80 male and 60 female students.

\section{Inclusion criteria}

Total 140 second professional medical students of both genders who gave informed consent with no incentive were included in the study.

\section{Exclusion criteria}

Students who did not give consent were excluded from the study.

The study period spanned about two weeks from 1 to 15 December 2017. A questionnaire was developed after a detailed review of relevant literature. Based on these a questionnaire was designed covering basic questions of antibiotics resistance and their usage. Before the commencement of main study, a small-scale pilot study was conducted among small number of students using the structured questionnaire. Based on the pilot study outcome, the questionnaire was modified and improved. This final validated questionnaire written in English was administered to the students and they were asked to mark their response whether they agree or disagree with the statement regarding knowledge, attitude questions. The responses obtained were recorded and tabulated. Questionnaire comprised of 20 questions. It was designed to get an overview of the students understanding of antibiotics usage and resistance entailing knowledge, attitude and practice. The questionnaire was further subdivided into three categories consisting of thirteen questions attributing to knowledge of antibiotics usage and resistance, while six questions pertained to attitude and one question pertained to practice towards antibiotic usage and resistance. The students were provided with questionnaire and were instructed to record their responses without consulting fellow students or resources like books, Google or Wikipedia etc. All the students responded voluntarily and were anonymous as they were asked not to write their names or roll number.

\section{Statistical analysis}

The recorded responses were evaluated for correct answers and presented as number and percentage.

\section{RESULTS}

The medical students showed fair knowledge about antibiotics and resistance. Percentages of fully correct answers was between $63-100 \%$ in all the statements regarding knowledge of antibiotics, the lowest percentage was the statement "paracetamol is not an antibiotic" and $63 \%$ of the students agreed, while highest correct responses were recorded in statement "Penicillin and amoxicillin are antibiotics" (100\%), followed by the statements "antibiotics can cause allergic reactions" (95.5\%) and "antibiotics are not indicated for every kind of pain and inflammation" (91\%).

As far knowledge about resistance was concerned, highest correct responses were observed in statement "antibiotic resistance is a phenomenon for which a bacterium loses its sensitivity to an antibiotic" $(88.2 \%)$, followed by the statement "inappropriate use of antibiotics can lead to antibiotic resistance and harm patient" (83\%) while the lowest percentage of correct responses was $78 \%$ in statement "Prescribing broad spectrum antibiotics when equally effective spectrum antibiotics are available increases resistance" (Table 1).

As far attitude of student was concerned, self-medication by the student was observed in $67 \%$ while $70 \%$ agreed that they had left over antibiotics at home, but only $42 \%$ committed that they take these left over antibiotics. $70 \%$ of students said that they stop taking medicines when they start feeling better. Only $31 \%$ students admitted that they take antibiotics after a simple phone call without any 
medical examination (Table 2). As far as practice was concerned the maximum students consult text books (31\%) as source of knowledge regarding resistance, followed by
Wikipedia $(21 \%)$, physician $(19 \%)$ and from peers $(9 \%)$ (Figure 1).

Table 1: Depicting knowledge.

\begin{tabular}{|lll|}
\hline Statements & Agree (\%) & Disagree (\%) \\
\hline Antibiotics are useful for treating bacterial infections & $90 \%$ & $10 \%$ \\
\hline Antibiotics can kill "good bacteria" present in an organism & $88 \%$ & $12 \%$ \\
\hline Antibiotics can cause secondary infections after killing good bacteria & $14 \%$ \\
\hline Antibiotics can cause allergic reactions & $86 \%$ & $4.5 \%$ \\
\hline Antibiotics are not appropriate for viral infections & $95.5 \%$ & $20 \%$ \\
\hline It is mandatory to finish the full course of antibiotics even if symptoms are improving & $80 \%$ & $70 \%$ \\
\hline How to interpret antibiograms & $66 \%$ & $30 \%$ \\
\hline $\begin{array}{l}\text { Antibiotic resistance is a phenomenon in which a bacterium loses its sensitivity to an } \\
\text { antibiotic }\end{array}$ & $88.2 \%$ & $11.8 \%$ \\
\hline Inappropriate use of antibiotics can lead to antibiotic resistance" and harm patient & $83 \%$ & $17 \%$ \\
\hline $\begin{array}{l}\text { Prescribing broad spectrum antibiotics when equally effective spectrum antibiotics are } \\
\text { available increases resistance }\end{array}$ & $78 \%$ & $22 \%$ \\
\hline Antibiotics are not indicated for every kind of pain and inflammation & $91 \%$ & $9 \%$ \\
\hline Penicillin and amoxicillin are antibiotics & $100 \%$ & $0 \%$ \\
\hline Paracetamol is not an antibiotic & $63 \%$ & $37 \%$ \\
\hline
\end{tabular}

Table 2: Depicting attitude.

\begin{tabular}{|c|c|c|}
\hline Statements & Yes & No \\
\hline Do you take antibiotics only when prescribed by the doctor? & 43 & 67 \\
\hline Do you take antibiotics without medical prescription? & 67 & 43 \\
\hline Do you have leftover antibiotics at home? & 70 & 30 \\
\hline Do you take antibiotics after a simple phone call with your doctor without medical examination? & 31 & 69 \\
\hline Do you usually use leftover antibiotics without consulting a doctor? & 42 & 58 \\
\hline Do you stop taking when you start feeling better? & 70 & 30 \\
\hline
\end{tabular}

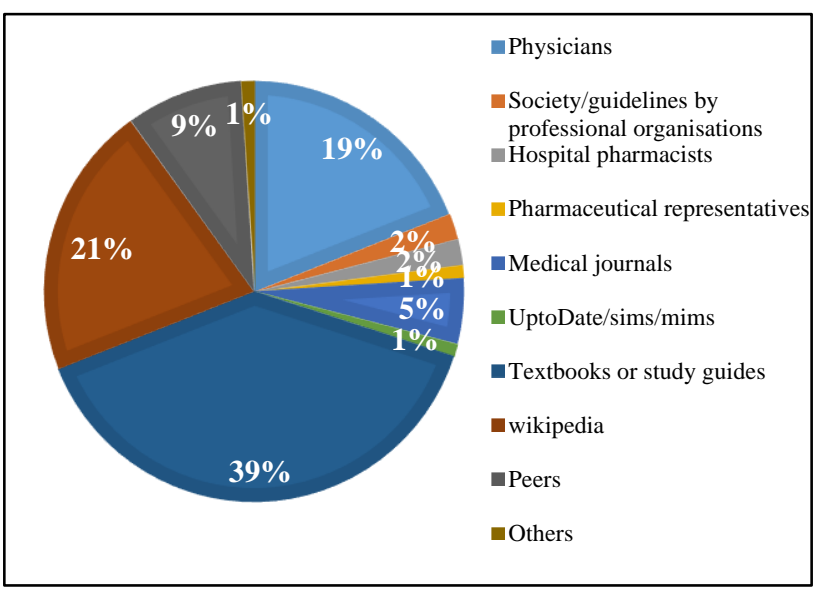

Figure 1: Depicting practice to learn about antibiotic usage and resistance.

\section{DISCUSSION}

Antibiotics are wonder drugs as they prevent and treat bacterial infections. However, their irrational use even by wrong prescribing behaviour of physician leads to antibiotic resistance because of change in the bacterial response to them. ${ }^{5}$ This results in spread of resistant strains of bacteria from person to person in the population.

Even indiscriminate use of antibiotics in animals also contributes to resistance as drug resistant bacteria from their faeces can contaminate crops to be eaten and find their way in human GIT. The infection caused by these resistant bacteria is difficult to treat and leads to increased medical costs, hospital stays, and mortality. ${ }^{6}$ Alexander Fleming who discovered penicillin in 1928, hailed as a "miracle drug" had also even then warned of bacteria becoming resistant to penicillin in his acceptance speech of Nobel Prize.

WHO has highlighted irrational use of antimicrobials as public health issue coupled with inadequate measures to control infections. Even WHO set the theme of World Health Day as 'Combat Antimicrobial Resistance: No Action Today, No Cure Tomorrow' ${ }^{6,7}$ Self-medication, irrational use, inadequate training for medical 
undergraduates regarding prescription of antimicrobials may contribute to the scenario. In Europe antimicrobial stewardship programme (2014) has been introduced by the government for improving antimicrobial prescribing behaviours of doctors. Antimicrobial resistance because of irrational and inadequate use of antimicrobials to control the spread of infections is a major health issue not only in developed but in developing countries also. Situation in a country like India and is of further concern as antimicrobials can be easily procured from the chemist's stores without physician's prescription facilitating selfmedication coupled with inadequate health infrastructure and widened doctor population gap.

Antibiotic use has been seen to be high in India with one recent surveillance study indicating 40.9 per cent of patients in the community on antibiotics, and even Physicians practicing in rural and public/government settings prescribed antimicrobials more frequently than those in urban and private settings $(83.8,81.9,68.3$ and $68.2 \%$ respectively). ${ }^{8,9}$

In our country the knowledge about usage and resistance of antimicrobials is imparted mainly in second professional undergraduate medical students covered under pharmacology and microbiology curriculum. It is necessary that these future doctors are equipped with better understanding of antimicrobial use and resistance. Therefore, with this aim the present study was conducted in second professional students to assess their knowledge regarding antimicrobial use and resistance.

There is paucity of studies regarding doctors' knowledge, attitude and practice (KAP) towards antimicrobial resistance. Therefore, medical students being future doctors were studied for KAP regarding antimicrobial resistance and for impact of second year curriculum in the present study to acquire the insight into this problem.

Results indicate that second professional medical students had fair knowledge about antibiotic usage and resistance. These results are in agreement with earlier reports documenting high knowledge of antimicrobial use and resistant among medical students. ${ }^{10-13}$ Recent study has even demonstrated the junior doctors usually have lower knowledge towards antimicrobial resistance compared to their seniors. ${ }^{14}$

To counter this situation UK government started with Antimicrobial stewardship programme (2014) to improve antimicrobial prescribing behaviours focusing on commitment and accountability for optimal antimicrobial use and interventions to avoid antimicrobial resistance. ${ }^{15,16}$

In India, the ASPIC programme (Antibiotic Stewardship, Prevention of Infection and Control) was initiated through the collaboration of the Office of the National Chair of Clinical Pharmacology, ICMR, and the Christian Medical College, Vellore, the primary workshop conducted in 2012.17
India has given due cognizance to the problem of Antimicrobial resistance (AMR) and to tackle this issue, Government of India has launched a "National Programme on Containment of Antimicrobial Resistance" under the $12^{\text {th }}$ five year plan (2012-2017).

The main objectives of this programme are to establish a laboratory based AMR surveillance system of 30 network labs in the country and to generate quality data on antimicrobial resistance for pathogens of public health importance, to strengthen infection control guidelines and practices and promote rationale use of antibiotics and to generate awareness among healthcare providers and in the community about rationale use of antibiotics. ${ }^{18}$

The World Health Organization (WHO) has also recommended training for medical undergraduates regarding the prudent prescription of antimicrobials to provide better knowledge of antimicrobial use and resistance. ${ }^{6}$ Programmes like antimicrobial stewardship should be encouraged to standardize the prescribing behaviours of our future doctors. ${ }^{19-21}$

The current study has demonstrated that the student's attitude was not adequate as compared to knowledge level. Self-medication by the student was observed in $67 \%$, while $70 \%$ agreed that they had left over antibiotics at home but only $42 \%$ committed that they take these left over antibiotics.

Number of authors have also reported inadequacy in attitude as compared to knowledge in their studies in concurrence to the results of current trial in medical students. ${ }^{10,11,13}$

A study done amongst final year pharmacy students at Malaysian public universities have also revealed a relatively good understanding a relatively good understanding of antibiotic resistance. However, their attitudes did not strongly correlate to their knowledge..$^{22}$

This underscores the need of more effort in updating the students regarding antibiotic usage and resistance and lying more emphasis in the core curriculum of their academics that can inculcate a moral responsibility toward the judicious use of antibiotics. ${ }^{23}$ A study from China has also emphasised the antibiotic knowledge and attitude education should be strengthened. ${ }^{24}$

As far practice towards resistance was concerned, most of them consult textbooks $(31 \%)$ as source of knowledge regarding resistance, followed by Wikipedia (21\%) and physician (19\%).

This suggest the increasing influence of the internet in the modern era, though the text books still retain the edge. A study done among Chinese medical students has also found resources frequently used were textbooks/study guides followed by peers, Wikipedia and smartphone applications similar to our results. ${ }^{25}$ 


\section{CONCLUSION}

The current study observed high score of knowledge than attitude in medical students regarding antibiotic usage and resistance. This underscores the disparity between the knowledge students have and their attitude. It is important to update them and create more awareness among them regarding antibiotic resistance. Indian Government initiative by launching National Programme on Containment of Antimicrobial Resistance" is going to be a game changer.

Funding: No funding sources

Conflict of interest: None declared

Ethical approval: The study was approved by the Institutional Ethics Committee (No: IECs I/18c/2017/410)

\section{REFERENCES}

1. Katy Askew. Antimicrobial resistance biggest threat to public-health. Available at: https://www.foodnavigator.com/.../Antimicrobialresistance-biggest-threat-to-public-health.

2. WHO. World Health Assembly addresses antimicrobial resistance 25 May 2015 Geneva. Available at: www.who.int/mediacentre/news/releases/2015/wha25-may-2015/en/.

3. Estimating the Economic Costs of Antimicrobial Resistance. RAND. Available at: https://www.rand.org/randeurope/research/projects/a ntimicrobial-resistance-costs.html.

4. What is superbug NDM-1? - Medical News Today. Available at: https://www.medicalnewstoday.com/articles/197616. php.

5. Kumar S, Little $\mathrm{P}$, Britten $\mathrm{N}$. Why do general practitioners prescribe antibiotics for sore throat? Grounded theory interview study. BMJ. 2003 Jan 18;326(7381):138.

6. World Health Organization. The evolving threat of antimicrobial resistance Options for action. Geneva: World Health Organization, 2012. Available at: http://whqlibdoc.who.int/publications/2012/9789241 503181_eng.pdf.

7. World Health Day. Antibiotic resistance: No action today, no cure tomorrow. 2011. Available at: http://www.who.int/mediacentre/news/statements/20 11/whd_20110407/en/index.html.

8. Chandy SJ, Thomas K, Mathai E, Antonisamy B, Holloway KA, Stalsby Lundborg C. Patterns of antibiotic use in the community and challenges of antibiotic surveillance in a lower-middle-income country setting: a repeated cross-sectional study in Vellore, South India. J Antimicrob Chemotherapy. 2012 Sep 3;68(1):229-36.

9. Kumari Indira KS, Chandy SJ, Jeyaseelan L, Kumar R, Suresh S. Antimicrobial prescription patterns for common acute infections in some rural \& urban health facilities of India. Indian J Med Res. 2008 Aug;128(2):165-71.

10. Suaifan GA, Shehadeh M, Darwish DA, Al-Ije H, Yousef AM, Darwish RM. A cross-sectional study on knowledge, attitude and behavior related to antibiotic use and resistance among medical and non-medical university students in Jordan. Afr J Pharmacy Pharmacol. 2012 Mar 15;6(10):763-70.

11. Afzal Khan AK, Banu G, Reshma KK. Antibiotic resistance and usage-a survey on the knowledge, attitude, perceptions and practices among the medical students of a Southern Indian teaching hospital. JCDR. 2013 Aug;7(8):1613.

12. Scaioli G, Gualano MR, Gili R, Masucci S, Bert F, Siliquini R. Antibiotic use: a cross-sectional survey assessing the knowledge, attitudes and Practices amongst Students of a School of Medicine in Italy. PLoS One. 2015 Apr 1;10(4):e0122476.

13. Sharma S, Jayakumar D, Palappallil DS, Kesavan KP. Knowledge, attitude and practices of antibiotic usage and resistance among the second year MBBS Students. Int J Basic Clin Pharmacol. 2016;5(3):899903.

14. Labi AK, Obeng-Nkrumah N, Bjerrum S, Aryee NA, Ofori-Adjei YA, Yawson AE, et al. Physicians' knowledge, attitudes, and perceptions concerning antibiotic resistance: a survey in a Ghanaian tertiary care hospital. BMC Health Services Res. 2018 Dec;18(1):126.

15. Centers for Disease Control and Prevention (CDC). Antibiotic resistance threats in the United States. 2013. Available http://www.cdc.gov/drugresistance/pdf/ar-threats2013-508.pdf.

16. Centers for Disease Control and Prevention (CDC). Core elements of hospital antibiotic stewardship programs. 2014. Available at: http://www.cdc.gov/getsmart/healthcare/pdfs/checkli st.pdf.

17. Chandy SJ, Michael JS, Veeraraghavan B, Abraham OC, Bachhav SS, Kshirsagar NA. ICMR programme on antibiotic stewardship, prevention of infection and control (ASPIC). Indian J Med Res. 2014 Feb;139(2):226-30.

18. National Centre for Disease Control. Available at: http://www.ncdc.gov.in/index1.php?lang=1\&level=1 \&sublinkid=39\&lid=74.

19. Hecker MT, Aron DC, Patel NP, Lehmann MK, Donskey CJ. Unnecessary use of antimicrobials in hospitalized patients: current patterns of misuse with an emphasis on the antianaerobic spectrum of activity. Arch Internal Med. 2003 Apr 28;163(8):972-8.

20. Owens Jr RC, Fraser GL, Stogsdill P. Antimicrobial stewardship programs as a means to optimize antimicrobial use insights from the Society of Infectious Diseases Pharmacists. Pharmacotherapy: J Human Pharmacol Drug Therapy. 2004 Jul;24(7):896908.

21. Paterson DL. The role of antimicrobial management programs in optimizing antibiotic prescribing within 
hospitals. Clin Infectious Dis. 2006 Jan 15;42(Supplement_2):S90-5.

22. Rajiah K, Ren WS, Jamshed SQ. Evaluation of the understanding of antibiotic resistance among Malaysian pharmacy students at public universities: an exploratory study. J Infection Public Health. 2015 May 1;8(3):266-73.

23. James H, Handu SS, Al Khaja KA, Otoom S, Sequeira RP. Evaluation of the knowledge, attitude and practice of self-medication among first-year medical students. Med Principles Pract. 2006;15(4):270-5.

24. Huang Y, Gu J, Zhang M, Ren Z, Yang W, Chen Y, et al. Knowledge, attitude and practice of antibiotics: a questionnaire study among 2500 Chinese students. BMC Med Education. 2013 Dec;13(1):163.

25. Yang K, Wu D, Tan F, Shi S, Guo X, Min Q, et al. Attitudes and perceptions regarding antimicrobial use and resistance among medical students in Central China. Springer Plus. 2016;5(1):779.

Cite this article as: Khajuria K, Kaur S, Sadiq S, Khajuria V. KAP on antibiotic usage and resistance among second professional medical students. Int $\mathbf{J}$ Basic Clin Pharmacol 2019;8:68-73. 